\title{
A STUDY OF DIFFERENT DOSES OF SUBLINGUAL MISOPROSTOL AFTER ORAL MIFEPRISTONE IN MEDICAL TERMINATION OF PREGNANCY
}

\author{
Sujatha Prabhu 1, Priyanka Krishnaswamy $H^{2}$, Achal Shetty ${ }^{3}$ \\ ${ }^{1}$ Professor, Department of Obstetrics and Gynaecology, ESIC Medical College and Postgraduate Insititute of Medical Sciences and \\ Research, Bangalore. \\ ${ }_{2}^{2}$ Post Graduate, Department of Obstetrics and Gynaecology, ESIC Medical College and Postgraduate Insititute of Medical Sciences and \\ Research, Bangalore. \\ ${ }^{3}$ Research Officer, Department of Community Medicine, RUHSA, Christian Medical College, Vellore.
}

\begin{abstract}
BACKGROUND: Though Mifepristone- Misoprostol combination is well established for early pregnancy termination, the optimal Misoprostol dose is still under much debate.

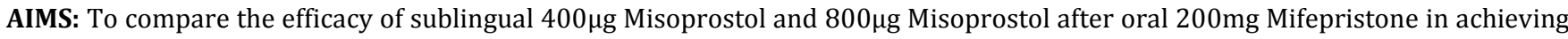
complete abortion, to study the induction abortion interval, complications and adverse effects seen with both groups. Setting 100 antenatal women requesting for medical termination of pregnancy of upto 63 days of gestation in ESI Medical College and Postgraduate Institute of Medical Sciences and Research, Karnataka in India. Design A Prospective Observational study.

METHODS AND MATERIAL: Study population was randomized into 2 groups of 50 patients each. Both groups received 200 mg

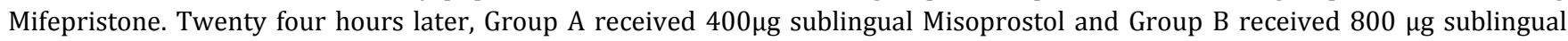
Misoprostol.

OUTCOME MEASURES: The primary outcome analyzed in this study is the efficacy of the two regimens in achieving complete abortion. Secondary outcome measures are Induction to Abortion interval and adverse effects like pain abdomen, nausea, vomiting, diarrhoea, fever and chills.

STATISTICAL ANALYSIS USED: Averages and proportions were calculated for the study and appropriate statistical tests like Chi Square Test, Fischer Exact Test and Student T Test were done using MiniTab version 16.

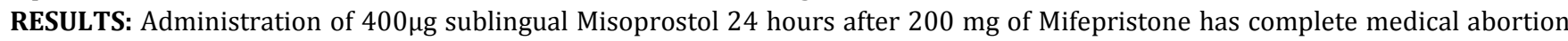
rates comparable with $800 \mu \mathrm{g}$ sublingual Misoprostol with significantly lesser side effects.

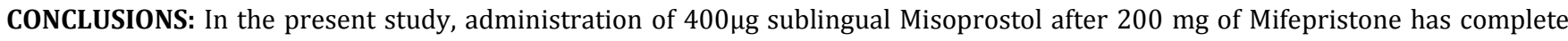
medical abortion rates comparable with $800 \mu \mathrm{g}$ sublingual Misoprostol with significantly lesser side effects. However further research with different doses and routes of administration of Misoprostol in required in a larger study population.
\end{abstract}

KEYWORDS: Two Different Doses of Sublingual Misoprostol in Early MTP. MeSH Terms Medical Abortion; Mifepristone; Misoprostol.

HOW TO CITE THIS ARTICLE: Sujatha Prabhu, Priyanka Krishnaswamy K, Achal Shetty. "A Study of Different Doses of Sublingual Misoprostol after Oral Mifepristone in Medical Termination of Pregnancy". Journal of Evolution of Medical and Dental Sciences 2015; Vol. 4, Issue 91, November 12; Page: 15673-15678, DOI: 10.14260/jemds/2015/2255.

INTRODUCTION: Worldwide, 46 million pregnancies end in induced abortions annually, of which 20 million are illegal/unsafe abortions. ${ }^{1} 13 \%$ of maternal mortality is due to unsafe abortions. $20-30 \%$ of unsafe ab nortions cause reproductive tract infections and $2 \%$ causes infertility. ${ }^{2}$ In India, around 10-12 million abortions take place annually, of which 15-20 thousand deaths are due to illegal/unsafe abortions. $^{3} 90 \%$ of induced abortions are in the first trimester alone. To reduce maternal mortality and morbidity, the provision of safe legal abortion to women in a variety of health care settings is the most important component of reproductive health services. Medical abortion offers greater potential for improving abortion access and safety, as it does not require an intensive infrastructure as in the case of surgical abortion and can offer privacy to the woman.

Financial or Other, Competing Interest: None.

Submission 22-09-2015, Peer Review 24-09-2015,

Acceptance 10-10-2015, Published 11-11-2015.

Corresponding Author:

Dr. Priyanka Krishnaswamy $K$,

No. 1062, $7^{\text {th }}$ A Main, $3^{\text {rd }}$ Block, Near Spencers,

Koramangala, Bangalore-560034,

Karnataka, India.

E-mail:priyanextdoor@yahoo.com

DOI:10.14260/jemds/2015/2255.
For first trimester abortions, an alternative safe and effective approach to surgical abortion is the combined use of Mifepristone and Misoprostol regimen as recommended by W.H.O. ${ }^{4}$ This is likely to make a positive impact on the reproductive health of women in India by providing support in addition to conventional family planning contraceptive. Mifepristone (RU-486), an antiprogestin, causes abortion by increasing uterine contractility by reversing the Progesterone- induced inhibition of contractions.

In addition, Mifepristone causes cervical collagen degradation, possibly because of increased expression of matrix metalloproteinase-2.5 Mifepristone also softens and dilates the cervix, causes decidual necrosis (Which leads to placental detachment), increases uterine lining prostaglandin release, increases uterine contractions, and enhances uterine sensitivity to administered prostaglandin. ${ }^{6}$

Misoprostol, a prostaglandin, binds to myometrial cells to cause strong myometrial contractions leading to expulsion of tissue. This agent also causes cervical ripening with softening and dilation of the cervix. ${ }^{6}$ Different combinations of Mifepristone and Misoprostol have been used in medical termination of pregnancy which traditionally varies with Mifepristone 100- $600 \mathrm{mg}$ orally followed by Misoprostol 200- $600 \mu \mathrm{g}$ orally or $800 \mu \mathrm{g}$ vaginally in multiple doses over 6- 72 hours. $^{5}$ 
The efficacy of Mifepristone- Prostaglandin regimen was not reduced by decreasing the dose of Mifepristone from $600 \mathrm{mg}$ to $200 \mathrm{mg}^{7}$ A pharmacokinetic study has shown that sublingual Misoprostol has the shortest onset of action, highest peak of concentration and greatest bioavailability among the three routes of administration. ${ }^{4} \mathrm{~A}$ previous study showed complete abortion occurred in $98.2 \%$ of women in the sublingual group and $93.8 \%$ in the vaginal group. ${ }^{8}$

Rates of serious infection dropped significantly after the joint change to buccal Misoprostol from vaginal Misoprostol and with routine administration of antibiotics. ${ }^{9}$ We therefore conducted a prospective observational study to find the optimal dose of sublingual Misoprostol either $400 \mu \mathrm{g}$ or $800 \mu \mathrm{g}$ that can be administered 24 hours after oral Mifepristone $200 \mathrm{mg}$, to achieve complete abortion with minimal side effects.

METHODS: We conducted a Prospective Comparative Hospital based study of 100 antenatal women attending the Obstetrics and Gynaecology outpatient department at ESIC MC Model Hospital, Rajajinagar, Bengaluru, Karnataka, India requesting for medical termination of pregnancy of upto 63 days of gestation, from October 2011 to October 2013. We obtained permission from the Hospital and Departmental Clinical Research Committee before starting this study.

CLINICAL MANAGEMENT AND DATA COLLECTION: Participants were randomly assigned in a 1:1 ratio by lottery method at the time of qualifying to enrol in the study. Hospital staff and participants were all aware of the study being conducted and an informed consent was taken from the patient.

ETHICAL APPROVAL: We obtained approval from the Hospital and Departmental Clinical Research Committee on $16^{\text {th }}$ September 2011 before starting this study.

STUDY POPULATION AND SETTING: 100 antenatal women with a single live intrauterine foetus of gestational age $\leq 9$ weeks, requesting for termination of pregnancy, eligible as per terms of the MTP Act, 1971, were randomized into 2 groups of 50 patients each. Both groups received $200 \mathrm{mg}$ Mifepristone orally. Twenty four hours later, Group A received $400 \mu \mathrm{g}$ sublingual Misoprostol and Group B received $800 \mu \mathrm{g}$ sublingual Misoprostol.

The exclusion criteria were-threatened and missed abortion: molar pregnancy: pregnancy with a coexisting Uterine fibroid or ovarian cyst: lactating women: medical disorders like Anaemia, Renal disease, Asthma: women on Corticosteroids or on Anticoagulant therapy and women allergic to Mifepristone or Misoprostol.

Informed consent was obtained for the procedure, the need for surgical procedure (Suction evacuation or dilatation and curettage) that may arise and for the necessary follow up in the present study. Gestational age was assessed by her L.M.P and pelvic examination, which was confirmed by ultrasonography. This also provided information regarding viability and site of implantation of pregnancy.

On day 1 of the admission, any complaints like pain abdomen, nausea, vomiting, diarrhoea, chills and fever were assessed. Oral Mifepristone $200 \mathrm{mg}$ was given under supervision. 24 hours later, the patient was administered with either $400 \mu \mathrm{g}$ or $800 \mu \mathrm{g}$ sublingual Misoprostol according to the group she was allotted to. Prior to administration of
Misoprostol, if any complaints like pain abdomen- mild, moderate or severe, nausea, vomiting, bleeding per vagina, diarrhoea, chills and fever were again noted. She was advised to place two tablets of $200 \mu \mathrm{g}$ Misoprostol beneath the tongue and to allow them to dissolve spontaneously. In the $800 \mu \mathrm{g}$ dosage group, the patient was advised to place four tablets sublingually.

All patients received Inj. Tetanus Toxoid and prophylactic antibiotics. Rh negative women were administered with $50 \mu \mathrm{g}$ of Inj. Anti D.

The patient was observed for a period of 4-8 hours. They were monitored hourly for the possible expulsion of products of conception, vaginal bleed and adverse effects such as nausea, vomiting, diarrhoea, abdominal cramps, chills and fever and treated accordingly. Once the patient reported passage of products of conception as assessed by history of expulsion of mass, clots or heavy bleed followed by decrease in pain abdomen and flow of vaginal bleed, this time was noted as the time of complete abortion and pelvic ultrasonography was repeated to confirm completion of abortion.

Patient was then discharged and during the follow up period of 1-14 days, they were requested to observe the days of vaginal bleeding and to fill the questionnaire administered to them to evaluate their side effects. They were provided with an emergency contact number to contact in case of excessive bleeding- soaking of two pads every hour for two consecutive hours, severe pain abdomen not relieved with medication, easy fatigability or a sustained fever of more than $100.4^{\circ} \mathrm{F}$. A follow up date was also provided to them on the $7^{\text {th }}$ and $14^{\text {th }}$ day post abortion.

They were also requested to record any of the above adverse effects and asked to return for follow up evaluation on Day 14. The patient was asked to review earlier if no bleeding occurs, if soaking of two pads occurred for two consecutive hours, had severe pain abdomen or if patient has a sustained fever of more than $100.4^{\circ} \mathrm{F}$.

In case patient had an ongoing pregnancy, missed abortion or an incomplete abortion even on the $14^{\text {th }}$ day after Misoprostol intake or requested for surgical termination of the pregnancy at any point in the study, she was classified as a failure of this study and surgical termination (Either vacuum aspiration or instrumental evacuation) was performed. Patient was counselled for a suitable contraceptive method after termination of pregnancy.

STATISTICAL ANALYSIS: The data obtained was analyzed using Chi Square Test, Fischer Exact Test and Student T Test were done using Minitab version 16.

STUDY OUTCOMES: The primary outcome was the efficacy of the two regimens in achieving complete abortion, defined as passage of products of conception with the assigned regimen without surgical intervention in the follow up period and confirmed by empty uterine cavity and ultrasonography. Secondary outcome measures were induction to abortion interval, number of days of bleeding and adverse effects which were nausea, vomiting, diarrhoea, abdominal cramps, chills and fever. This was evaluated with the help of a questionnaire on which pain abdomen was recorded as mild (Felt but easily tolerated), moderate (Uncomfortable enough to interfere with normal activity) or severe (Incapacitating normal activity). The presence or absence of diarrhoea defined as passage of three or more stools per day was recorded along with the presence or absence of nausea, 
vomiting, chills and fever of more than $1004^{\circ} \mathrm{F}$ for 14 days post abortion.

The above terminologies in our study were defined as Ongoing Pregnancy- No products of conception expelled and cardiac activity present on ultrasound: Missed miscarriageNo products of conception expelled and ultrasound showing evidence of a gestational sac without cardiac activity: Incomplete miscarriage- Endometrial Thickness of $\geq 20 \mathrm{~mm}$ on ultrasound even after 14 days of Misoprostol administration: Induction to Abortion Interval- The time interval between administration of Misoprostol and the clinically estimated- ultrasonologically confirmed time of abortion which was noted, as explained above.

\section{RESULTS:}

Study Group: Demographic characteristics between both the groups (Table 1) were analyzed with respect to age, weight, haemoglobin status, parity and gestational age.

Successful Medical Abortion: 92\% of patients in Group A had a complete abortion with $400 \mu \mathrm{g}$ Misoprostol and $95 \%$ of patients in Group B had a complete abortion with $800 \mu \mathrm{g}$ Misoprostol (Table 2). The p value was 1 between both the groups and hence there was no statistical significance between the complete medical abortion rates of both groups. There were 7 failures in the study. 1 patient in Group A and 1 patient in Group B requested for a surgical abortion after intake of Misoprostol citing pain abdomen following intake of Misoprostol as reason to elect surgical abortion. The other 5 failures of this study- 3 in Group A and 2 in Group B had an incomplete abortion at the end of 14 days and needed a surgical evacuation to complete the abortion.

Abortion Interval: The mean abortion interval after intake of Misoprostol was 3.52 hours in Group A and 3.09 hours in Group B (Table 3). There was no difference between the mean Induction to Abortion Interval between Group A and Group B (p value 0.097).

No. of Days of Bleeding in Both Groups: In Group A, the mean duration of bleeding was 7.85 days and was 7.38 days in Group B (Table 4). The difference between the mean average duration of bleeding between both the groups was not significant.

\begin{tabular}{|c|c|c|c|c|c|}
\hline $\begin{array}{l}\text { ADVERSE EFFECTS (Table 5)Demographic } \\
\text { Characteristics }\end{array}$ & $\begin{array}{l}\text { Group A } \\
(n=50)\end{array}$ & Range & $\begin{array}{l}\text { Group B } \\
(n=50)\end{array}$ & Range & $P$-value \\
\hline Age (Years) & 25.66 & 18- 35 & 25.18 & 18- 33 & 0.574 \\
\hline Weight (kg) & 55.36 & 38- 82 & 56.04 & 39- 89 & 0.761 \\
\hline Hemoglobin (gm/dl) & 10.5 & 9- 14.2 & 10.4 & $9-13.6$ & 0.88 \\
\hline \multicolumn{4}{|l|}{ Parity } & & \\
\hline Primigravida & 5 & 9 & 0.12 & & \\
\hline Parous & 45 & 41 & 0.24 & & \\
\hline Prev. abortion & 4 & 5 & $>0.05$ & & \\
\hline \multicolumn{4}{|l|}{ Gestational Age (Days) } & & \\
\hline$\leq 49$ & 12 & 13 & 0.81 & & \\
\hline $50-56$ & 23 & 17 & 0.22 & & \\
\hline $57-63$ & 15 & 20 & 0.29 & & \\
\hline
\end{tabular}

\begin{tabular}{|c|c|c|c|c|c|}
\hline $\begin{array}{c}\text { P value } \\
\text { between groups- 1 }\end{array}$ & $\begin{array}{c}\text { Duration } \\
\text { of Gestation }\end{array}$ & $\begin{array}{c}\text { No. } \\
\text { of Patients }\end{array}$ & $\begin{array}{c}\text { Successful } \\
\text { complete } \\
\text { medical abortion }\end{array}$ & $\begin{array}{c}\text { Percent } \\
\text { of Number } \\
\text { Aborted }\end{array}$ & $\begin{array}{c}\text { Requiring } \\
\text { instrumental } \\
\text { evacuation }\end{array}$ \\
\hline \multirow{3}{*}{ Group A } & $\leq 49$ & 12 & 11 & $91.60 \%$ & 1 \\
\cline { 2 - 6 } & $50-56$ & 23 & 21 & $91.30 \%$ & 2 \\
\cline { 2 - 6 } & $57-63$ & 15 & 14 & $93.30 \%$ & 1 \\
\cline { 2 - 6 } & Total & 50 & 46 & $92 \%$ & 4 \\
\hline \multirow{3}{*}{ Group B } & $\leq 49$ & 13 & 13 & $100 \%$ & 0 \\
\cline { 2 - 6 } & $50-56$ & 17 & 17 & $100 \%$ & 0 \\
\cline { 2 - 6 } & $57-63$ & 20 & 17 & $85 \%$ & 3 \\
\cline { 2 - 6 } & Total & $\mathbf{5 0}$ & $\mathbf{4 7}$ & $\mathbf{9 5 \%}$ & $\mathbf{3}$ \\
\hline
\end{tabular}

\begin{tabular}{|c|c|c|c|c|c|c|}
\hline Group & N & Mean (hours) & Range (hours) & Std. Deviation & t value & p value \\
\cline { 1 - 5 } A & 46 & 3.52 & $1-6$ & 1.243 & \multirow{2}{*}{0.097} \\
\cline { 1 - 4 } B & 47 & 3.09 & $1-5$ & 1.265 & 1.670 & \\
\hline \multicolumn{7}{|c|}{ Table 3: Mean Abortion Interval } \\
\hline
\end{tabular}




\begin{tabular}{|c|c|c|c|c|c|c|c|}
\hline \multirow{2}{*}{ Group } & N & $\begin{array}{c}\text { Mean } \\
\text { (days) }\end{array}$ & $\begin{array}{c}\text { Range } \\
\text { (days) }\end{array}$ & Std. Deviation & t value & Degree of freedom & Pvalue \\
\hline A & 46 & 7.85 & $4-17$ & 3.169 & 0.792 & & \multirow{2}{*}{0.43} \\
\hline B & 47 & 7.38 & $4-14$ & 2.524 & & \multirow{2}{*}{ Table 4: Number of Days of bleeding } \\
\hline \multicolumn{7}{|c|}{}
\end{tabular}

\begin{tabular}{|c|c|c|c|c|c|c|}
\hline & \multicolumn{2}{|c|}{ Group $A(n=50)$} & \multicolumn{2}{|c|}{ Group B $(n=50)$} & \multirow[b]{2}{*}{ Chi square } & \multirow[b]{2}{*}{ P value } \\
\hline & Number & Percentage & Number & Percentage & & \\
\hline \multicolumn{7}{|l|}{ Lower Abdominal Pain } \\
\hline At Admission & 0 & & 1 & 2 & & \\
\hline Mifepristone to Misoprostol & 0 & & 1 & 2 & & \\
\hline After Misoprostol & 50 & 100 & 50 & 100 & & \\
\hline Mild & 25 & 50 & 3 & 6 & & $<0.001$ \\
\hline Moderate & 24 & 48 & 23 & 46 & 0.04 & 0.84 \\
\hline Severe & 1 & 2 & 24 & 48 & & $<0.001$ \\
\hline \multicolumn{7}{|l|}{ Nausea } \\
\hline At Admission & 10 & 20 & 16 & 32 & 1.87 & 0.17 \\
\hline Mifepristone to Misoprostol & 10 & 20 & 17 & 34 & 2.48 & 0.11 \\
\hline After Misoprostol & 10 & 20 & 29 & 58 & 15.17 & $<0.001$ \\
\hline \multicolumn{7}{|l|}{ Vomiting } \\
\hline At Admission & 2 & 4 & 8 & 16 & & 0.09 \\
\hline Mifepristone to Misoprostol & 3 & 6 & 8 & 16 & & 0.11 \\
\hline After Misoprostol & 7 & 14 & 20 & 40 & 8.57 & 0.003 \\
\hline \multicolumn{7}{|l|}{ Diarrhoea } \\
\hline At Admission & 0 & 0 & 0 & 0 & & \\
\hline Mifepristone to Misoprostol & 2 & 4 & 3 & 6 & & $>0.99$ \\
\hline After Misoprostol & 15 & 30 & 27 & 54 & 5.9 & 0.01 \\
\hline \multicolumn{7}{|l|}{ Chills } \\
\hline At Admission & 0 & 0 & 0 & 0 & & \\
\hline Mifepristone to Misoprostol & 0 & 0 & 3 & 6 & & \\
\hline After Misoprostol & 12 & 24 & 46 & 92 & & $<0.001$ \\
\hline \multicolumn{7}{|l|}{ Fever } \\
\hline At Admission & 0 & 0 & 0 & 0 & & \\
\hline Mifepristone to Misoprostol & 0 & 0 & 1 & 2 & & \\
\hline After Misoprostol & 18 & 36 & 29 & 58 & 4.85 & 0.02 \\
\hline \multicolumn{7}{|c|}{ Table 5: Adverse Effects } \\
\hline
\end{tabular}

\begin{tabular}{|c|c|c|c|c|c|c|c|c|c|c|c|c|c|c|c|}
\hline & \multicolumn{2}{|c|}{$\begin{array}{l}\text { Complete } \\
\text { Abortion }\end{array}$} & \multirow{2}{*}{ 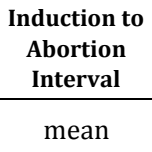 } & \multicolumn{2}{|c|}{$\begin{array}{c}\text { Pain } \\
\text { Abdomen }\end{array}$} & \multicolumn{2}{|c|}{ Nausea } & \multicolumn{2}{|c|}{ Vomiting } & \multicolumn{2}{|c|}{ Diarrhoea } & \multicolumn{2}{|c|}{ Fever } & \multicolumn{2}{|c|}{ Chills } \\
\hline & $\mathrm{n}$ & $\%$ & & $\mathrm{n}$ & $\%$ & $\mathrm{n}$ & $\%$ & $\mathrm{n}$ & $\%$ & $\mathrm{~N}$ & $\%$ & $\mathrm{n}$ & $\%$ & $\mathrm{n}$ & $\%$ \\
\hline $\begin{array}{c}\text { Group A } \\
(n=50)\end{array}$ & 46 & 92 & 3.52 & mild-25 & 50 & 10 & 20 & 7 & 14 & 15 & 30 & 18 & 36 & 12 & 24 \\
\hline $\begin{array}{r}\text { Group B } \\
(n=50)\end{array}$ & 47 & 95 & 3.08 & $\begin{array}{c}\text { moderate- } \\
24\end{array}$ & 48 & 29 & 58 & 20 & 40 & 27 & 54 & 29 & 58 & 46 & 92 \\
\hline & & To & Compc & of results & bta & 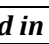 & tud & $t w$ & $G r$ & $\boldsymbol{A}$ & Gro & & & & \\
\hline
\end{tabular}

ABDOMINAL PAIN: All patients in the study had pain abdomen of some degree. No patients in Group A had pain abdomen at admission or between Mifepristone to Misoprostol and 1 patient in Group B had pain abdomen at admission and between Mifepristone to Misoprostol. In Group A, 50\% had mild pain abdomen, $48 \%$ had moderate pain and $2 \%$ had severe pain abdomen after Misoprostol. In Group B, 6\% had mild pain abdomen, $46 \%$ had moderate pain and $48 \%$ had severe pain abdomen after Misoprostol administration.

Incidence of mild pain abdomen was significantly more in Group A than in Group B (p value- <0.001). Incidence of moderate pain abdomen was not significantly different between the groups A and B ( $p$ value-0.84). Incidence of severe pain abdomen was significantly more in Group B than in Group A ( $\mathrm{p}$ value $-<0.001$ )

Journal of Evolution of Medical and Dental Sciences/ eISSN- 2278-4802, pISSN- 2278-4748/ Vol. 4/ Issue 91/ Nov. 12, 2015
NAUSEA: In Group A, 20\% had nausea at admission, 20\% between Mifepristone to Misoprostol and 20\% had new onset nausea after Misoprostol intake. 5 patients in Group A continued to have nausea from admission up to after intake of Misoprostol, and have not been included as an adverse effect of either of the two drugs.

In Group B, 32\% had nausea at admission, 34\% between Mifepristone to Misoprostol and 58\% had new onset nausea after Misoprostol intake. 10 patients in Group A continued to have nausea from admission up to after intake of Misoprostol, and have not been included as an adverse effect of either of the two drugs. There were significantly more number of patients with nausea after administration of $800 \mu$ g sublingual Misoprostol in Group B ( $p$ value $<0.001$ ). 
VOMITING: In Group A, 4\% had vomiting at admission, 6\% between Mifepristone to Misoprostol and 14\% had new onset vomiting after Misoprostol intake. 1 patient in Group A continued to have vomiting from admission up to after intake of Misoprostol, and who have not been included as an adverse effect of either of the two drugs.

In Group B, 16\% had vomiting at admission, 16\% between Mifepristone to Misoprostol and 40\% had new onset vomiting after Misoprostol intake. 10 patients in Group A continued to have vomiting from admission up to after intake of Misoprostol, and who have not been included as an adverse effect of either of the two drugs. There were significantly more number of patients with vomiting after administration of $800 \mu \mathrm{g}$ sublingual Misoprostol in Group B ( $p$ value-<0.05).

DIARRHOEA: In Group A, $4 \%$ had diarrhoea between Mifepristone to Misoprostol and 30\% had diarrhoea after Misoprostol. In Group B, 6\% had diarrhoea between Mifepristone to Misoprostol and 54\% had diarrhoea after Misoprostol. No patients had diarrhoea at admission. There were significantly more number of patients with diarrhoea after administration of $800 \mu \mathrm{g}$ sublingual Misoprostol in Group B (p value 0.01).

CHILLS: In Group A, no patients had chills at admission and between Mifepristone to Misoprostol and 24\% had chills after Misoprostol. In Group B, no patients had chills at admission, $6 \%$ had chills between Mifepristone to Misoprostol and 92\% had chills after Misoprostol. There were significantly more number of patients with chills after administration of $800 \mu \mathrm{g}$ sublingual Misoprostol ( $p$ value$<0.001$ ).

FEVER: Group A, no patients had fever at admission and between Mifepristone to Misoprostol and 36\% had fever after Misoprostol. In Group B, no patients had fever at admission, 2\% had fever between Mifepristone to Misoprostol and 58\% had fever after Misoprostol. There were more number of patients with fever after administration of $800 \mu \mathrm{g}$ sublingual Misoprostol, and this was statistically significant ( $\mathrm{p}$ value0.02 )

\section{DISCUSSION:}

Main Findings: In the combined Mifepristone-Misoprostol regime for termination of pregnancy with gestation $<63$ day, administration of low dose sublingual Misoprostol $(400 \mu \mathrm{g})$ after 24 hours of $200 \mathrm{mg}$ Mifepristone is effective in achieving successful complete medical abortion with lower incidence of adverse effects when compared with $800 \mu \mathrm{g}$ sublingual Misoprostol.

Strengths and weaknesses of the study: The major strength of this trial was compared with previous studies was a pregnancy gestation and live pregnancy validated by ultrasound in all of the participants and the use of ultrasound immediately after the reported expulsion to look for complete abortion. Additionally, the study compared the efficacy of two varied strengths of Misoprostol administered by the same route, i.e., sublingual. The trial population was homogeneous with a $100 \%$ short-term follow-up rate at 7 and 14 days.

Some limitations to this study may apply as this was a small study conducted in a unit of a teaching hospital. Large multi-centric studies with a mixed ethnic population would be of value in this field. Another limitation to the current study may be that the outcomes evaluated were all shortterm.

Interpretation: Before applying the results to other populations and settings, several factors have to be considered. Overall, the study population had a low body mass index and was very homogeneous, and the study aimed to only include healthy women with no a priori risks.

CONCLUSIONS: In the present study, Group A had 92\% complete abortion rate and Group B had 95\% complete abortion rate ( $p$ value-1). Both regimens were equally successful in achieving a complete medical abortion. There was no significant difference in mean Induction to Abortion Interval between both the groups with it being $3.52 \mathrm{hrs}$ in Group A and 3.08hrs in Group B (p value-0.097).

Adverse effects of Misoprostol are reduced in Group A compared to Group B. There is higher incidence of severe pain abdomen in Group B (48\%) and mild pain abdomen in Group A (50\%) though it was observed that all patients had some degree of pain abdomen in the study.

There was lower incidence of nausea, vomiting, diarrhoea, fever and chills observed in Group A.

The statistical results conclude that $400 \mu \mathrm{g}$ sublingual Misoprostol is as effective as $800 \mu \mathrm{g}$ sublingual Misoprostol in achieving complete abortion with lesser incidence of side effects (Table 6).

Contribution to Authorship: All authors had full access to the data in the study and take responsibility for the integrity of the data and the accuracy of the data analysis. All authors reviewed and approved the final version of the paper.

Details of Ethics Approval: The study was approved by ESI Hospital Ethical Committee.

ACKNOWLEDGEMENTS: We wish to thank all the families who participated in this trial, the dedicated staff.

\section{REFERENCES:}

1. World Health Organization, Department of Reproductive Health and Research. Safe Abortion: Technical and policy guidance for health systems. WHO Library Cataloguing-in-Publication Data, 2003 September. Geneva.

2. Ahman E, Shah I. World Health Organization. Unsafe Abortion: Global and Regional Estimates of the incidence of unsafe abortion and associated mortality in 2008, UNDP/UNFPA/WHO/World Bank Special Programme of Research,2011.

3. Kumar SS, Antony SCZK, Kapur SCA, Togra SLM. Termination of Pregnancy in First Trimester- Medical Option. MJAFI 2005; 61: 151- 154.

4. Tang OS, Chan CC, Ng EH, Lee SW, Ho PC. Pharmacokinetics of different routes of administration of Misoprostol. Hum Reprod.

5. 2011 October $17 ; 17(2): 332-336$.

6. Williams. Abortion. In: Cunningham FG, Leveno KJ, Bloom SL, Hauth JC, Dwight JR, Spong CY. Williams Obstetrics. 23rded. New York: McGraw Hill 2010; p.232.

7. R Suzanne, Trupin, Moreno C. Medical Abortion: Overview and Management. MedGenMed Ob/Gyn \& Women's Health [Online]. Medscape General Medicine. 2002; 4(1). 
8. http://www.medscape.com/viewarticle/429755_3 [Date of Access- 23/ 09/2015].

9. HoPC. Comparison of two doses of mifepristone in combination with misoprostol for early medical abortion: a randomised trial.

10. BJOG 2000; 107: 524-530.
11. Tang OS, Chan CC, Ng EH, Lee SW, Ho PC. A prospective, randomized, placebo-controlled trial on the use of mifepristone with sublingual or vaginal misoprostol for medical abortions of less than 9 weeks gestation. Hum Reprod. 2003 Nov; 18 (11): 2315- 2318.

12. Fjerstad M, Trussell J, Sivin I, Lichtenberg ES, Cullins V. Rates of serious infection after changes in regimens for medical abortion. N Engl J Med. 2009 Jul 9; 361(2):145-15. 